\title{
Л.А. Гаман
}

\section{«ИСТОРИЮ Я ВИЖУ В ЭСХАТОЛОГИЧЕСКОЙ ПЕРСПЕКТИВЕ...»: Н.А. БЕРДЯЕВ О СОВЕТСКОЙ РОССИИ В ПОЗДНИЙ ПЕРИОД ТВОРЧЕСТВА (1939-1948 гг.)}

\begin{abstract}
Рассматриваются представления русского религиозного мыслителя Н.А. Бердяева (1874-1948) о Советской России в поздний период творчества. Подчеркивается сложность предпринятого им анализа советской системы. Отмечается, что в качестве религиозного мыслителя, для которого было характерно эсхатологическое восприятие христианства, он положительно оценивал революцию 1917 г. и советское строительство, несмотря на многие негативные их стороны. Анализируются его представления о технической цивилизации и ее неоднозначном влиянии на современный мир, в том числе на Советскую Россию.
\end{abstract}

Ключевые слова: Советская Россия; революция; техническая цивилизация.

Советский период является одним из наиболее сложных и трагичных этапов российской истории. Среди объяснительных версий революции 1917 г. и советского строительства в России важное место занимают концепции русских религиозных мыслителей первой волны эмиграции, получившие широкое признание на родине лишь в постсоветский период. Особо подчеркнем вклад выдающегося ученого и педагога, профессора Б.Г. Могильницкого, признанного лидера Томской историографической школы, в изучение богатейшего идейно-теоретического наследия русских религиозных эмигрантских авторов, начатое на рубеже 1980-1990-х гг.

В данной работе освещаются представления о Советской России Н.А. Бердяева (1874-1948) в поздний период его творчества, которые являются важной составной частью его богатейшего творческого наследия, продолжающего вызывать научный интерес российских и зарубежных исследователей вплоть до настоящего времени [1]. Представления этого религиозного мыслителя о Советской России отличаются семантической сложностью, дискуссионностью, отражают противоречивый характер советского строительства, обусловленный различными факторами, как эндогенными, так и международными по своему характеру. Их ведущая тональность определялась его настойчивым стремлением «встраивать» советский период истории в единый исторический процесс в режиме «долгого времени», что усложняло его концепцию советской истории и расширяло его исследовательские возможности. Современники Бердяева отмечали неоднозначный характер его взглядов на революцию 1917 г. и советское строительство, что отражено в работах Ф.А. Степуна [2], Г.П. Федотова [3, 4], М. Карповича [5], других авторов. До настоящего времени сохраняет актуальность монография Н. Полторацкого, в которой изложены представления мыслителя о российской истории в целом [6]. Среди современных исследователей вызывают интерес работы Б.Г. Могильницкого [7, 8], А.А. Ермичева [9], О.В. Волкогоновой [10]. Автором данной статьи в ряде работ уделяется специальное внимание анализу представлений Бердяева о Русской революции 1917 г. и советской истории [11. С. 23 $129,12]$.

В качестве основных источников для данной работы выступают произведения Бердяева, написанные им в 1930-1940-е гг., в том числе не публиковавшиеся ранее в России, ныне хранящиеся в фондах Российского государственного архива литературы и искусства (РГАЛИ). Важным источником также являются эгодокументы, принадлежавшие ему и его современникам, обращение к которым способствует углубленному пониманию отдельных аспектов его концепции революции 1917 г. и советского строительства, как и пониманию своеобразия эпохи, в которой ему довелось жить и творить.

Касаясь взглядов Бердяева позднего периода творчества, необходимо принимать во внимание культурноисторический и политический контекст конца 19301940-х гг., обусловленный целым рядом важных событий. Достаточно указать на Вторую мировую войну и вклад СССР в победу над фашистской Германией и ее союзниками, на начало холодной войны с сопутствующей ей гонкой вооружений и становление двуполярного мира со свойственным ему «блоковым мышлением». Важен и такой факт, как создание атомной бомбы, когда стало предельно ясно, что победителей в новой войне не будет, что заостряло проблему международной интеграции. Свою роль играла и напряженная атмосфера, характерная для российской эмигрантской среды в 1930-1940-е гг., обусловленная главным образом неоднозначностью интерпретаций и оценок революции 1917 г. в России и ее последствий. В такой непростой обстановке Бердяев, являвшийся сторонником персоналистического социализма, следуя эсхатологическому пониманию христианства, делая акцент на концепте преображения мира (что, по его убеждению, соответствовало русской идее), предложил свое видение советского строительства в свете комплекса христианских идей с доминирующей идеей направленности истории в сторону «преображения» общества и с учетом мировых тенденций развития. Комплекс этих его историко-религиозных представлений сохраняет свою научную ценность и актуальность, 
несмотря на полемический характер многих выводов и оценок.

В своем исследовании Советской России Бердяев опирался на междисциплинарную исследовательскую стратегию, сочетающую в себе достижения различных наук на основе принципа «взаимной дополнительности» [11. С. 24-41]. Одним из главных для него как христианского мыслителя являлся метод религиозного символизма [2. 132-147]. В соответствии с ним фундаментальным признавалось теоретическое положение о «двухуровневой» структуре истории, состоящей из уровня собственно исторического, пространственновременного, и метаисторического, коррелятивно связанных друг с другом. Подчеркивая богочеловеческую природу истории, Бердяев рассматривал обращение к комплексу христианских идей как способ углубленного изучения истории, позволявший находить новые грани и смысловые уровни исторических событий. Для понимания основной интенции его размышлений о советской истории существенным является его указание на то, что выявление негативных ее проявлений при всей своей важности - не должно заслонять положительных ее сторон. «Вопрос совсем не в том, есть ли в Советской России много дурного, за что ее с большой легкостью могут обличать... - писал он в 1946 г., - а в том, что в ней нужно увидеть задатки развития к лучшей жизни, и что все нужно делать, чтобы помогать этому развитию» [13]. При этом Бердяев не ограничивался констатацией положительных или отрицательных сторон советской действительности, диалектическое единство которых он настойчиво подчеркивал. Свою версию Советской России он моделировал «на пересечении» ретроспективного анализа сюжетов российской истории, анализа настоящего и видения ее будущего с учетом вызовов современности. Такой подход позволял ему находить линии преемственности в развитии страны, культурно-историческую обусловленность многих явлений советской истории. С этой же целью он использовал в своем анализе сравнительно-исторический метод, сравнивая отдельные сюжеты российской истории и истории западных стран, в частности революцию 1917 г. в России и Французскую революцию, советскую индустриализацию и подобные процессы в Европе [12].

Русскую революцию 1917 г. наряду с Первой мировой войной Бердяев рассматривал как рубежное событие, открывавшее «новую историческую эру», отличительной чертой которой являлось формирование социального строя, противоположного, по его мнению, исчерпавшей себя капиталистической системе, базированной на принципах индивидуализма, частной собственности, конкуренции. Констатируя системный кризис европейской цивилизации, выразившийся в двух мировых войнах, революции 1917 г. в России, других масштабных конфликтах XX в., Бердяев был далек от мысли рассматривать его как некий исторический тупик. Напротив, по его убеждению, христианское человечество, следуя евангельскому Откровению, этому центральному факту истории, призвано было искать пути преодоления кризиса, перехода на качественно иной уровень развития. Эту глубоко религи- озную исходную установку мыслителя очень точно выразил его современник: «Кризис был для него не явлением вырождения, а кризисом роста» [14. С. 141]. В свете поисков путей преодоления кризиса он, независимо от политической конъюнктуры, положительно оценивал «смелый опыт» русского народа по построению социалистического общества. Самую возможность социалистического строительства, начатого Россией, он связывал с ее «антибуржуазным и антикапиталистическим характером», сформировавшимся исторически, с особенностями российского менталитета [15]. Выражая свое отношение к самой сути советского строительства, он отмечал: «Вопрос тут не в эксцессах, которые, конечно, подлежат нравственному осуждению, а в самом социальном перевороте, который хочет уничтожить эксплуатацию человека человеком» [13]. Не сомневаясь в принадлежности христианскому периоду истории «опыта русского коммунизма», который «ставит перед христианством новые задачи» [16. С. 194], Бердяев акцентировал внимание на положительных сторонах пореволюционного строительства, значимых в режиме «долгого времени», в перспективе формирования в мировом масштабе «нового общества», религиозного в своей основе.

Необходимость формирования такого общества являлась для него очевидной и в связи с основными тенденциями развития индустриального общества с его массовым производством, активизацией широких народных масс и массовой культурой. «Современный мир требует большей социальной справедливости, отмечал он в своем докладе на международной встрече в Женеве в 1947 г., - он идет к социальной организации общества, употребляя эти слова в широком смысле. Этого требует самый процесс индустриального развития... В нынешней своей стадии индустриальный капитализм перестал быть либеральным и индивидуальным. Он принял коллективные формы. Старый мир был несправедлив, и это одна из причин его гибели. В стремлении к большей социальной справедливости правда современного движения общества» [17. Л. 16]. В соответствии со своим пониманием «миссии русского народа в мире» [18. Л. 8; 19. С. 275] он отводил лидирующую роль России в формировании нового общества, основу которого должно было составлять признание высшей ценности человеческой личности. В этой части размышлений Бердяева отчетливо просматривается его стремление учесть сложную диалектику глобального и национального в историческом процессе.

Констатируя неизбежность перехода к новому этапу исторического развития, высоко оценивая начатый русским народом «необычайно смелый опыт» построения более справедливого социального строя [19], Бердяев в то же время критически воспринимал многие стороны советского политического режима с характерными для него насильственными методами воздействия на общество и репрессированием свободы. Предельно полно он выразил свое отношение к нему в одном из писем в 1946 г.: «Отношение к советской власти не может не быть двойственным. Она делает много дурного, и непосредственно у меня к ней нет никакой симпатии. Но она является единственной ис- 
торической властью, принужденной защищать Россию перед лицом мира» [20. С. 263]. По его убеждению, систематическое ущемление и подавление свободы в стране являлось основным препятствием для раскрытия положительного потенциала советской системы, определяло многие ее негативные стороны, способствовало формированию «тяжелой моральной атмосферы» в стране. Касаясь этой сложной проблемы, он писал в июле 1945 г.: «Если Сов. Россия (так в тексте. Л.Г.) хочет создать новую жизнь, - а я хочу верить, что она хочет, - то она должна поставить во главу угла достоинство и ценность человеческой личности, чего мы нигде не видим...» [21. Л. 15]. Не случайно свою последнюю книгу «Царство духа и царство Кесаря» Бердяев написал, как отмечает Степун, протестуя против ущемлений свободы в Советской России [2. С. 124]. В этой связи показательно внимание мыслителя к специфике советской морали, многое объясняющей в пространстве коммуникации Советской России. Ее ядро составлял моральный релятивизм, связанный с коммунистической идеологией, способствовавший грубым нарушениям естественных прав и свобод человека в стране. Моральный релятивизм, отрицающий универсальную мораль, полагал Бердяев, лежал также в основе внешней политики советского государства, что особенно отчетливо проявилось накануне Второй мировой войны. «Отрицание универсальной морали, объединяющей все человечество, - писал он в 1940 г., - ведет коммунизм к оправданию всех средств борьбы для достижения ими своих целей» [22. Л. 16-17]. Одновременно с тем, отмечал он, советская мораль парадоксальным образом задавала и высокие стандарты социального поведения советских граждан [15, 23].

На рубеже 1930-1940-х гг. Бердяев, подобно другим эмигрантским авторам, например Федотову [11. С. 201], усмотрел признаки завершения революции в России и начала «контрреволюции». «Многих удивляют, - писал он в 1940 г. - изменения, происходящие в Советской России. Между тем как в этих изменениях есть типические черты конца революций. В известном смысле можно сказать, что в стране советов происходит контр-революция (так в тексте. - Л.Г.), и она делается теми же силами, которые делали революцию. Во всяком случае революция кончена, нет более ее стихии и пафоса» [18. Л. 3]. При сохранении марксистской символики и риторики, подчеркивал он, в стране происходили глубокие изменения, свидетельствовавшие о преодолении революции, что нашло свое символическое трагическое выражение в развязывании террора против самих творцов революции. «Такова фальшь и ложь московского процесса, - негодовал Бердяев, - неслыханного в своей низости. Правящий слой отвратительно разделался со старыми коммунистами. Троцкий, который остался верен интернациональному революционному коммунизму, объявляется контр-революционером (так в тексте. - Л.Г.), фашистом, агентом Гестапо, защитником капитализма. Без этой лжи и этой расправы совсем нельзя сохранить старые символы марксизма и коммунизма, остались бы люди, которые могут изобличать совершающуюся комедию» [Там же. Л. 4-5]. Важными показателями «контр-революции» в России для Бердяева также стали появление новых форм социального неравенства, зарождение «новой буржуазии», а также непрерывно возраставшая милитаризация страны в национальных интересах, а не в интересах мировой революции [Там же. Л. 6]. Убедительным аргументом в пользу преодоления революции в Советской России для Бердяева выступали также такие положительные изменения, происходившие в Советской России в 1930-1940-е гг., как сокращение гонений на религию и возврат к целому ряду консервативных по своей природе ценностей: патриотизму, семье, личной собственности. Можно предположить, что одним из источников информации о происходивших в пореволюционный период сдвигах в повседневной жизни советского человека для Бердяева стали письма Е. Герцык [24], часть из которых была опубликована под названием «Письма оттуда» в нескольких номерах эмигрантского журнала «Современные записки», о которых он упоминает в своей философской автобиографии [25. С. 153]. Большое положительное значение он видел в советском неогуманизме, симптомы которого наметились в 1930-е гг., находил положительные стороны советской трудовой этики, связанной с принципом социального служения [18. Л. 8-9], а по окончании Второй мировой войны указывал на провозглашение в Советской России «права на труд, права на отдых, права на образование» [26].

Бердяев полагал, что в комплексе причин, вызвавших многие обозначенные выше трансформации в России, ведущее место принадлежит воздействию «процессов жизни», прежде всего социальных ожиданий народных масс. «Средний человек масс требует, - писал он, - чтобы революция кончилась... Правительство Сталина принуждено уступать процессам жизни...» [Там же. Л. 5]. Подчеркнем значение, которое придавалось мыслителем понятию «процесс жизни» в работах позднего периода творчества. Не давая ему развернутого определения, он тем не менее постоянно оперировал им, анализируя те или иные стороны советской реальности, подчеркивая их роль в преодолении многочисленных изъянов советской системы или объясняя еe положительные стороны, в частности необычайный динамизм и социальный титанизм советского народа. Так, рассуждая о положении церкви в послевоенный период в СССР, он призывал к толерантному отношению к ее политике вынужденного взаимодействия с властью, полагая, что «жизненные процессы» помогут преодолеть его отрицательные стороны [13]. Сходной позиции по отношению к положению церкви в СССР в послевоенный период придерживался Степун, однако, в отличие от Бердяева, резко критиковавший поддержку сталинского режима некоторыми высшими церковными иерархами, определявшими церковную политику [27. С. 155-156]. В более широком смысле внимание к «процессам жизни», согласно Бердяеву, являлось необходимым условием объективного научного исследования. По сути, речь шла методологическом подходе, согласно которому в исследовательской практике необходимым являлся всесторонний анализ культурно-исторического контекста как условия снижения вероятности поверх- 
ностных или предвзятых интерпретаций «на основе отвлеченных принципов» [28]. Уместно в данном случае подчеркнуть актуальность для современной историографии подобного подхода к проблеме контекста [29].

Положительные достижения Советской России наряду с ее решающим вкладом в победу над фашистской Германией, полагал Бердяев, способствовали росту ее международного авторитета в послевоенный период. Отмечая рост влияния СССР в послевоенном мире, в особенности на страны второго и третьего эшелонов развития [19], Бердяев скептически относился к обвинениям советского государства в империалистических притязаниях. Касаясь этой проблемы, между прочим, сложно связанной с традиционными национальными интересами России, он писал: «Несправедливо обвинение Советской России в склонности к националистическому империализму. Но ей свойствен некоторый социальный империализм, желание социального влияния на другие страны, прежде всего на страны балканские...» [26]. Вспомним в данном случае его оригинальную интерпретацию идеи о Москве как Третьем Риме, одной из ключевых в его интерпретации революции 1917 г. и советского строительства. С началом холодной войны Бердяев прилагал усилия к преодолению «блокового» принципа в международной политике, который стал весомым фактором изоляции СССР от западных капиталистических стран. Отмечая негативное значение изоляции от Европы для «освободительных процессов» в Советской России [26], он особенно подчеркивал опасность реактуализации в историческом сознании народа архаического комплекса «свой-чужой», враждебного свободе, способствовавшего закреплению деспотизма власти в стране, затруднявшего формирование «европейской федерации народов», необходимой для обеспечения устойчивого развития послевоенного мира, немыслимой, по его убеждению, без России [19. С. 278].

В комплексе размышлений Бердяева о Советской России, ее мировом призвании и лидирующей роли в становлении нового типа общества значительное место занимает его стремление учитывать при анализе советской системы различные аспекты становления технической цивилизации, ключевые элементы которой (наука, техника, массовое общество, массовая культура) изменили не только среду обитания человека, но и всю систему взаимоотношений в мире, напрямую затронув и Советскую Россию. Впервые обратившись к данной проблеме на рубеже 1920-1930-х гг. [30], он вновь и вновь возвращался к ней в поздний период творчества. В этой связи большой интерес вызывает доклад Бердяева «Человек в технической цивилизации», с которым он выступил на международной встрече в Женеве в 1947 г. [17]. В докладе в развернутом виде представлены его зрелые размышления о природе современного индустриального общества и перспективах его дальнейшего развития. Положительно оценивая научно-технические достижения XX в., Бердяев одновременно указывал на неоднозначные последствия их широкого применения в разных сферах общества. Характер революций, войн и тоталитарных режимов XX в., многие экономические проблемы, прежде всего безработицу, он напрямую связывал с результатами и последствиями научно-технического прогресса [17. Л. 7]. Указывал он и на глубокие изменения в самой природе современного общества, которое он квалифицировал как организованное, типологически иное, чем общество органическое, характеризовавшееся неразрывной связью человека с религией и природой. Рассматривая технику как фактор, влекущий за собой многочисленные угрозы человеческой экзистенции, - а после создания атомной бомбы и угрозу существования самой человеческой цивилизации [Там же. Л. 8], - Бердяев был далек от отрицания ее, рассматривая ее в качестве важного ресурса для повышения качества жизни людей, настаивая на необходимости ее подчинения духовным началам. «Техника должна быть подчинена духу, - настойчиво подчеркивал мыслитель, - машина стать послушным орудием человека. Это означает гуманизацию техники, имеющей тенденцию стать бесчеловечной и бездушной. Нельзя остановить научные открытия, которые делает человек, на том основании, что их применения впоследствии могут быть опасны» [Там же. Л. 25].

В контексте становления технической цивилизации он рассматривал советскую индустриализацию [12], имевшую свои отличительные черты, обусловленные спецификой советской политической системы и особенностями российского менталитета [17. Л. 11]. Ценным в условиях формирования технической цивилизации Бердяеву представлялось сохранение положительных свойств русского народа, особенно «коммюнотарности», воспитанной православием, свойства, связанного с «соборностью», не тождественного коллективизму, характерному для индустриальной эпохи с ее массовым производством. «Много раз уже указывали, подчеркивал он, - что механизированная и рационализированная индустрия ведет к утрате индивидуального и индивидуальности. Все производится в сериях. Это есть царство безличности. Все становится коллективным, подчеркиваю, коллективным, а не коммюнотарным, что есть очень большая разница. Коммюнотарность есть реальная общность, братство людей, она предполагает изменение и преображение людей, она органична. Коллективизм есть принудительное и механическое сцепление людей» [Там же. Л. 13; 15].

В числе первых Бердяев обратил внимание на глубокую внутреннюю взаимообусловленность возрастания этатизма в современном мире и развития науки и техники, особенно направлений, связанных с военными целями и задачами. Он подчеркивал общемировой характер тенденции укрепления государства в условиях технической цивилизации, конечно, специфически преломившейся в советской политической системе с ее исторически сложившимися традициями власти. «Этатизм совсем не есть особенность только советского строя, - настаивал он, - это явление мировое. И огромную роль тут играет возрастающая сила техники» [17. Л. 10]. Усиление власти государства в ущерб интересам личности, широкая практика государственного регулирования в экономике, распространившаяся в мире в XX в. в результате мировых войн, расширение возможностей для манипуляций общественным сознанием, 
инерционное действие психологии войны, ярко проявившееся в «блоковом мышлении» [19], - все это с разной степенью выраженности присутствовало, по объективному наблюдению Бердяева, в любом современном государстве в условиях технической цивилизации.

Важной составляющей становления технической цивилизации Бердяев считал демократизацию общества, «активное вступление в историю человеческих масс, огромных количеств». Этими своими размышлениями он внес вклад в изучение массового общества и его психологии, наряду с такими его исследователями, как Э. Фромм, Х. Ортега-и-Гассет, Э. Канетти, Ф. Степун. Предостерегая от упрощенных интерпретаций данной проблемы, он настаивал на строгой дифференциации понятий «масса» («толпа») и «народ», представляющий собой соборный коллектив, имеющий свою нормативно-ценностную систему. Демократизация общества, происходившая на фоне интенсивного вытеснения на периферию общественного сознания религиозных верований и традиционных ценностей народа («консервативных элементов»), вела к понижению общего культурного уровня населения, широкому распространению массовой культуры, к антропологическому кризису. Настаивая на глубоком различии между «народом» и «массой», Бердяев писал: «Масса... формируется прессой, пропагандой партий, спортом, радио, кинематографом, популярной литературой невысокого качества. Это не может не означать понижения человеческого типа. И это свойственно технической эпохе...» [17. Л. 12; 21]. Понижение качества подлинной культуры в Советской России, вызванное революцией 1917 г., в интерпретации Бердяева сложно коррелировалось с общемировой тенденцией формирования массовой культуры.

Таким образом, Бердяев осуществлял исследование советской реальности в глобальной перспективе, с учетом общемировых тенденций, учитывая при этом своеобразие России. О глубине его переживаний за судьбы
России на закате жизни свидетельствует фрагмент одного из его писем (1946): «Очень сложно мое отношение к Советской России и ко всему тому, что там происходит. Я готов защищать Советскую Россию, как мою родину, вижу в ней и правду, которую многие не хотят видеть. Но многое меня возмущает и отталкивает, особенно в последнее время. Не происходит тех изменений к лучшему, на которые можно было рассчитывать после потрясения войны. Трудно примириться с таким количеством лжи и насилия. Все это очень мучительно. Но я продолжаю верить в великую миссию России» [20. С. 260]. Не раз уже отмечалось, что свойственное ему видение советского строительства нередко вызывало непонимание и острую критику, едва ли всегда аргументированную. Несомненно, Бердяев, стремясь обосновать ведущее место Советской России в построении нового типа общества, недооценивал масштабы практиковавшегося в СССР насилия, не ставил во всей остроте проблемы цены советских достижений. Однако следует признать его заслугой стремление рассматривать советский период как один из этапов единой российской истории, в рамках которого диалектически переплелись положительные и отрицательные процессы, при глубокой убежденности в том, что жизненные силы русского народа, его лучшие национальные свойства, позволят преодолеть многочисленные «срывы» пореволюционного строительства и раскрыть положительный потенциал советской системы. И это несмотря на то, что, вопреки прогнозам Бердяева, Россия вернулась к капиталистической системе отношений. Существенным является и то, что избранный им ракурс исследования революции и советского строительства в свете христианских идей при одновременно внимательном отношении к основным тенденциям мирового развития, с учетом достижений современной науки позволил ему поставить ряд важных проблем, сохраняющих свою актуальность вплоть до настоящего времени.

\section{ЛИТЕРАТУРА}

1. Н.А. Бердяев и единство европейского духа / под ред. В. Поруса. М. : Библейско-Богословский ин-т св. апостола Андрея, 2007.336 с. (Сер. «Религиозные мыслители»).

2. Степун Ф.А. Мистическое мировидение. Пять образов русского символизма / пер. с нем. Г. Снежинской, Е. Крепак и Л. Маркевич. СПб. : Владимир Даль, 2012. 479 с.

3. Федотов Г.П. Ответ Н.А. Бердяеву // Федотов Г.П. Собр. соч. : в 12 т. / прим. С.С. Бычкова. М. : Мартис, 2004. Т. 9: Статьи американского периода. С. 194-210.

4. Федотов Г.П. Н.А. Бердяев - мыслитель // Федотов Г.П. Собр. соч. : в 12 т. / прим. С.С. Бычкова. М. : Мартис, 2004. Т. 9: Статьи американского периода. С. 278-291.

5. Карпович М. Комментарии. В поисках «третьего исхода» (о статье Н.А. Бердяева) // Новый журнал. 1953. № 32. С. $281-287$.

6. Полторацкий Н. Бердяев и Россия (Философия истории России Н.А. Бердяева). Нью-Йорк : О-во друзей русской культуры, 1967. 270 с.

7. Могильницкий Б.Г. Бердяев о Русской революции // Новая и новейшая история. 1995. № 6. С. 54-67.

8. Могильницкий Б.Г. История исторической мысли ХХ века : курс лекций. Томск : Ид-во Том. ун-та, 2001. Вып. 1: Кризис историзма. 206 с.

9. Ермичев А.А. Три свободы Николая Бердяева // Ермичев А.А. Имена и сюжеты русской философии. СПб., 2014. С. 241-266.

10. Волкогонова О.Д. Бердяев. М. : Молодая гвардия, 2010. 390 с.

11. Гаман Л.А. Революция 1917 г. и советская история в освещении русской религиозной эмигрантской мысли. Томск : Изд-во Том. ун-та, 2008. $332 \mathrm{c}$.

12. Гаман Л.А. Русская революция 1917 г. и модернизация: Н.А. Бердяев о некоторых аспектах революции в России // Вестник Томского государственного университета. 2018. № 429. С. 111-116.

13. Бердяев Н. Судьба русской церкви // Российский государственный архив литературы и искусства (РГАЛИ). Ф. 1496. Бердяев. Оп. 1. Ед. хр. 223. Статьи 1945-1946 гг.

14. Вильчковский К. Н.А. Бердяев и мировой кризис // Новоселье. 1949. № 39/40. С. 139-143.

15. Бердяев Н.А. Личность и общинность (коммюнотарность) в русском сознании // Бердяев Н.А. На пороге новой эпохи : сб. ст. // Бердяев Н.А. Истина и Откровение. Пролегомены к критике Откровения. СПб. : Изд-во РХГИ, 1997. С. $235-261$.

16. Бердяев Н.А. Пути гуманизма // Бердяев Н.А. На пороге новой эпохи : сб. ст. // Бердяев Н.А. Истина и Откровение. Пролегомены к критике Откровения. СПб. : Изд-во РХГИ, 1997. С. 180-194.

17. Бердяев Н.А. Человек в технической цивилизации // РГАЛИ. Ф. 1496. Бердяев. Оп. 1. Ед. хр. 103. 27 л. 
18. Бердяев Н.А. Перерождение коммунизма в Советской России (1939-1940) // РГАЛИ. Ф. 1496. Бердяев. Оп. 1. Ед. хр. 219. Л. 3-10.

19. Бердяев Н.А. Третий исход // Новый журнал. 1953. № 32. С. 271-280.

20. «В четвертом измерении пространства...»: письма Н.А. Бердяева кн. И.П. Романовой 1931-1947 / публ., предисл. и ком. В. Аллоя и А. Добкина // Минувшее. 1994. № 16. С. 209-264.

21.Бердяев Н.А. О личности и толпе (Ответ Б.Г. Пантелеймонову) // РГАЛИ. Ф. 1496. Бердяев. Оп. 1. Ед. хр. 223. Статьи $1945-1946$ гг. Л. 11-15.

22. Бердяев Н.А. Советская Россия и мировая война (1939-1940) // РГАЛИ. Ф. 1496. Бердяев. Оп. 1. Ед. хр. 219. Л. 14-23.

23. Бердяев Н.А. Две морали // Бердяев Н.А. На пороге новой эпохи : сб. ст. // Бердяев Н.А. Истина и Откровение. Пролегомены к критике Откровения. СПб. : Изд-во РХГИ, 1997. С. 195-209.

24. Перекличка через «железный занавес»: письма Е. Герцык, В. Гриневич, Л. Бердяевой / [публ., сост., вступ. ст. и коммент. Т.Н. Жуковской; подгот. текста М.А. Котенко]. М. : Дом русского зарубежья им. Александра Солженицына : Русский путь, 2011.560 с.

25. Бердяев Н.А. Самопознание. М. : ДЭМ, 1990. 336 с.

26. Бердяев Н.А. Почему Запад не понимает Советской России // РГАЛИ. Ф. 1496. Бердяев. Оп. 1. Ед. хр. 223. Статьи 1945-1946 гг.

27. Степун Ф.А. Письма / сост., археограф. работа, вступ. ст. к тому и разделам В.К. Кантора. М. : РОССПЭН, 2013.683 с.

28. Бердяев Н.А. Нужно пережить судьбу русского народа // РГАЛИ. Ф. 1496. Бердяев. Оп. 1. Ед. хр. 223. Статьи $1945-1946$.

29. Юрганов А.Л. Культурная история России. Век двадцатый : статьи и публикации разных лет. М. ; СПб. : Центр гуманитарных инициатив, $2018.384 \mathrm{c}$.

30. Бердяев Н.А. Человек и машина (проблема социологии и метафизики техники) // Путь, 1933. № 38 (май). С. 3-37.

Lidia A. Gaman, Seversk Technological Institute - branch of National Research Nuclear University “MEPhi” (Seversk, Russian Federation) (Seversk, Russian Federation). E-mail: GamanL@yandex.ru

\section{"I SEE HISTORY IN THE ESCHATOLOGICAL PERSPECTIVE...": N.A. BERDYAEV ABOUT SOVIET RUSSIA IN HIS LATE WORK PERIOD (1939-1948)}

Keywords: Soviet Russia, revolution, technological civilization.

The aim of the article is to study Berdyaev's historical and religious views about Soviet Russia concerning his late work period. There is a modern researchers' interest in his oeuvre. The relevance of the subject is proved. The sources are analyzed, basis of which are Berdyaev's works, written in 1930-1940, as well as the thinker's ego-documents and his contemporaries. The peculiarities of Berdyaev's methodology being cross-disciplinary in character, within which the achievements of various social sciences and humanities were combined on the basis of mutual complementarity, are considered. The key significance for his religious symbolism methodology as a cognition method related to a Christian paradigm of history is pointed out. For Berdyaev's work the importance of the cultural and historical context peculiar to 1930-1940 is emphasized. The large-scale conflicts of the first half of the 20th century including two world wars and the Russia revolution of 1917 consolidated his view of the European civilization systemic crisis which he regarded not as a historical impasse, but as a growth crisis presumed finding ways to overcome it.

Following the eschatological understanding of Christianity, emphasizing the idea of transforming the world, associating the Russian idea with it, being a supporter of personalist socialism, Berdyaev offered his vision of the Soviet construction in the light of the Christian ideas complex with the dominant idea in the history orientation towards the formation of a new society. The complexity of his approach to Soviet Russia connected with his desire to take into account the world development trends in the 20th century, due to the technological civilization formation with its characteristic development of science and technology, mass production, mass society, the increasing state role, is emphasized. It is noted the significance of Berdyaev's ideas complex for his interpretation of various Soviet reality angles whether Soviet industrialization or Soviet etatism is. The positive and negative aspects of Soviet society identified by him are analysed, and his ideas of the dialectic unity is discussed. His thoughts about occurred revolution in Soviet Russia between 1930-1940 are considered. The consequences he touched upon both negative, especially repression, and positive, contributed to the normalization of the Soviet people lives, are covered. As proposed by Berdyaev, positive achievements of Soviet Russia promoted the growth of its international authority are noted. The negative significance for the post-war world of "block thinking" is pointed out. In his opinion, the main obstacle to the exposure of the Soviet system positive potential was the freedom repression in the USSR.

The conclusion about the content and relevance of the concept of the Russian revolution in 1917 and Berdyaev's Soviet history, despite the controversial type of his conclusions and assessments, is made.

\section{REFERENCES}

1. Porus, V. (2007) N.A. Berdyaev i edinstvo evropeyskogo dukha [N.A. Berdyaev and the unity of the European spirit]. Moscow: St. Andrew's Biblical Theological Institute.

2. Stepun, F.A. (2012) Misticheskoe mirovidenie. Pyat' obrazov russkogo simvolizma [Mystical vision. Five images of Russian symbolism]. Translated from German by G. Snezhinskaya, E. Krepak, L. Markevich. St. Petersburg: Vladimir Dal'. pp. 112-220.

3. Fedotov, G.P. (2004) Sobranie sochneniy: v $12 t$. [Collected Works in 12 vols]. Vol. 9. Moscow: Martis. pp. 194-210.

4. Fedotov, G.P. (2004) Sobranie sochneniy: $v 12$ t. [Collected Works in 12 vols]. Vol. 9. Moscow: Martis. pp. 278-291.

5. Karpovich, M. (1953) Kommentarii. V poiskakh tret'ego "iskhoda" (o stat'e N.A. Berdyaeva) [Comments. In search of a "third exodus" (about N.A. Berdyaev's article)]. Novyy zhurnal. 32. pp. 281-287.

6. Poltoratsky, N. (1967) Berdyaev i Rossiya (Filosofiya istorii Rossii N.A. Berdyaeva) [Berdyaev and Russia (N.A. Berdyaev's Philosophy of Russian History)]. New York: Obshchestvo Druzey Russkoy kul'tury.

7. Mogilnitsky, B.G. (1995) Berdyaev o Russkoy revolyutsii [Berdyaev about the Russian revolution]. Novaya i noveyshaya istoriya. 6. pp. 54-67.

8. Mogilnitsky, B.G. (2001) Istoriya istoricheskoy mysli XX veka [The historical thought of the 20th century]. Tomsk: Tomsk State University. pp. 92-109.

9. Ermichev, A.A. (2014) Imena i syuzhety russkoy filosofii [Names and Plots of Russian Philosophy]. St. Petersburg: Nauka. pp. 241-266.

10. Volkogonova, O.D. (2010) Berdyaev [Berdyaev]. Moscow: Molodaya gvardiya.

11. Gaman, L.A. (2008) Revolyutsiya 1917 g. i sovetskaya istoriya v osveshchenii russkoy religioznoy emigrantskoy mysli [The 1917 Revolution and Soviet history in the coverage of Russian religious emigrant thought]. Tomsk: Tomsk State University.

12. Gaman, L.A. (2018) Russian revolution of 1917 and modernization: Nikolai Berdyaev on some aspects of the revolution in Russia. Vestnik Tomskogo gosudarstvennogo universiteta - Tomsk State University Journal. 429. pp. 111-116. (In Russian). DOI: 10.17223/15617793/429/13

13. Berdyaev, N. (n.d.) Sud'ba russkoy tserkvi [The fate of the Russian Church]. The Russian State Archive of Literature and Art. Fund 1496. Berdyaev. List 1. File 223.

14. Vilchkovsky, K. (1949) N.A. Berdyaev i mirovoy krizis [Berdyaev and the global crisis]. Novosel'e. 39/40. pp. 139-143.

15. Berdyaev, N.A. (1997) Istina i Otkrovenie. Prolegomeny k kritike Otkroveniya [Truth and Revelation. Prolegomes to the criticism of Revelation]. St. Petersburg: Russian Christian Institute for the Humanities. pp. 235-261. 
16. Berdyaev, N.A. (1997) Istina i Otkrovenie. Prolegomeny k kritike Otkroveniya [Truth and Revelation. Prolegomes to the criticism of Revelation]. St. Petersburg: Russian Christian Institute for the Humanities. pp. 180-194.

17. Berdyaev, N.A. (n.d.) Chelovek $v$ tekhnicheskoy tsivilizatsii [Man in technical civilization]. The Russian State Archive of Literature and Art. Fund 1496. Berdyaev. List 1. File 103.

18. Berdyaev, N.A. (n.d.) Pererozhdenie kommunizma v Sovetskoy Rossii (1939-1940) [The rebirth of communism in Soviet Russia (1939-1940)]. The Russian State Archive of Literature and Art. Fund 1496. Berdyaev. List 1. File 219. pp. 3-10.

19. Berdyaev, N.A. (1953) Tretiy iskhod [Third Exodus]. Novyy zhurnal. 32. pp. 271-280.

20. Berdyaev, N. (1994) V chetvertom izmerenii prostranstva...: Pis'ma N.A. Berdyaeva kn. I.P. Romanovoy 1931-1947 [“In the fourth dimension of space ...": Letters from N.A. Berdyaev to Prince I.P. Romanov, 1931-1947]. Minuvshee. 16. pp. 209-264.

21. Berdyaev, N.A. (n.d.) O lichnosti $i$ tolpe (Otvet B.G. Panteleymonovu) [On the individual and the crowd (Reply to B.G. Panteleimonov)]. The Russian State Archive of Literature and Art. Fund 1496. Berdyaev. List 1. File 223. pp. 11-15.

22. Berdyaev, N.A. (n.d.) Sovetskaya Rossiya i mirovaya voyna (1939-1940) [Soviet Russia and World War (1939-1940)]. The Russian State Archive of Literature and Art. Fund 1496. Berdyaev. List 1. File 219. pp. 14-23.

23. Berdyaev, N.A. (n.d.) Na poroge novoy epokhi [On the threshold of a new era]. [s.1.; s.n.] pp. 195-209.

24. Gertsyk, E. (2011) Pereklichka cherez "zheleznyy zanaves": Pis'ma E. Gertsyk, V. Grinevich, L. Berdyaevoy [Roll call through the "Iron Curtain": Letters from E. Gertsyk to V. Grinevich, L. Berdyaeva]. Moscow: Russkiy put'. pp. 23-354.

25. Berdyaev, N.A. (1990) Samopoznanie [Self-knowledge]. Moscow: DEM

26. Berdyaev, N.A. (n.d.) Pochemu Zapad ne ponimaet Sovetskoy Rossii [Why the West does not understand Soviet Russia]. The Russian State Archive of Literature and Art. Fund 1496. Berdyaev. List 1. File 223.

27. Stepun, F.A. (2013) Pis'ma [Letters]. Moscow: ROSSPEN.

28. Berdyaev, N.A. (n.d.) Nuzhno perezhit' sud'bu russkogo naroda [It is necessary to survive the fate of the Russian people]. The Russian State Archive of Literature and Art. Fund 1496. Berdyaev. List 1. File 223.

29. Yurganov, A.L. (2018) Kul'turnaya istoriya Rossii. Vek dvadtsatyy. Stat'i i publikatsii raznykh let [The cultural history of Russia. Twentieth Century. Articles and publications of various years]. Moscow; St. Petersburg: Tsentr gumanitarnykh initsiativ.

30. Berdyaev, N.A. (1933) Chelovek i mashina (Problema sotsiologii i metafiziki tekhniki) [Man and Machine (The Problem of Sociology and Metaphysics of Technology)]. Put'. 38. pp. 3-37. 